\title{
A COMPARATIVE STUDY OF ADVANCED OXIDATIVE PROCESSES. DEGRADATION OF CHLORINATED ORGANIC COMPOUNDS IN ULTRAFILTRATION FRACTIONS OF KRAFT PULP BLEACHING EFFLUENT
}

\begin{abstract}
Oxidative pre-treatment methods such as the Fenton oxidation, ozonation, and photocatalytic treatment have been compared in reducing adsorbable organic halogens (AOX) and chlorophenolic compounds in untreated kraft pulp bleaching effluent. Their efficiency was also studied on effluent ultrafiltration fractions. The Fenton treatment removed all analyzed chlorophenolic compounds from the effluent. Ozonation and photocatalysis appeared to be much less effective methods. The efficiency of the Fenton oxidation appeared to be more pronounced in higher molecular weight effluent fractions. This suggests a novel design, where the filtration stage can be placed after the oxidation, and the high-molecular weight fraction is returned to the Fenton treatment.
\end{abstract}

\section{INTRODUCTION}

Water, one of our most important natural resources is threatened by misuse, pollution, as well as economy and population growth. The pulp and paper industry is one of the most important users of fresh water and it must therefore take care of the environment by minimizing emissions to the aquatic environment [1]. For this reason, various new technologies have been introduced and applied to reduce the environmental load of wastewaters. Typically wastewaters can be treated by biological methods, or by more specific chemical methods designed to remove selectively undesired substances. During the past few decades, there have been environmental concerns associated to the pulp

${ }^{1}$ Laboratory of Organic Chemistry, Department of Chemistry, University of Helsinki, A.I. Virtasen Aukio 1, FIN-00560 Helsinki, Finland, corresponding author, e-mail: juhnis@live.com

${ }^{2}$ Laboratory of Applied Chemistry, Department of Chemistry. University of Jyväskylä, Survontie 9, FIN-40500 Jyväskylä, Finland. 
bleaching process and its effluents. Pulp washing that usually follows each bleaching stage requires substantial amounts of water, although water consumption in pulp bleaching has been decreasing substantially in the past decades [2]. This is mainly due to improved washing equipment and more efficient washing practices, such as high-degree counter-current washing. However, the current trend to minimize the overall consumption of fresh water has simultaneously resulted in elevated concentrations of detrimental substances in process waters and effluents, which in turn has a negative effect on the quality of receiving natural waters [3].

Any substance entering the bleaching process, regardless of its origin, must exit as a product or solid waste or by emission to the air or aqueous environment. There are a vast number of various chemical compounds present in the circulating filtrates and effluents from a bleach plant. It has been estimated [1] that only 10-30\% of them have been identified. Characterization of these compounds is necessary in order to choose the most appropriate treatment method for effluents. A common approach to characterize effluent quality is to measure certain sum parameters. Adsorbable organic halogens (AOX) is a sum parameter that indicates the amount of adsorbable organically bound halogens. It is very useful as small part of chlorine dioxide used in bleaching can cause chlorine atoms to bind with organic matter where it forms chlorinated organic compounds, such as chlorophenols that do not easily decompose in nature. Some of these compounds are reportedly toxic, mutagenic and carcinogenic [4]. Due to their harmfulness to the nature, effective treatment methods are needed to reduce the load of chlorinated organic compounds in wastewaters before their discharge into receiving water bodies.

In general, activated sludge process represents the most common technology for the secondary treatment of pulp mill effluents [1]. However, some organic substances present in pulp mill effluents are so biorecalcitrant that biological treatment may not give satisfactory results. To solve this problem, oxidative pre-treatments, which incorporate the formation of highly reactive hydroxyl radicals, are capable to degrade or mineralize many complex organic compounds present in pulp mill effluents [5-7]. The operational costs of these technologies are, however, significantly higher than those of a biological treatment. Nevertheless, in some cases the most suitable approach is to combine chemical oxidation with filtration prior to biological treatment [6] as shown in Fig. 1. The partially oxidized effluent is subjected to a filtration step, and the fraction with larger and less biodegradable substances (retentate) is returned to chemical oxidation. This effectively generates permeate, more biodegradable intermediate effluent fraction. Moreover, this arrangement apparently removes harmful chloroaromatics such as polychlorinated phenols, catechols and guaiacols in a very efficient way. In addition, this method may facilitate the recycling and/or removal of catalysts prior to biological treatment.

Various chemical oxidation treatments - advanced oxidation processes (AOPs) - have been extensively studied as a way to reduce the AOX load of bleaching effluents. 
These methods include direct UV photolysis, $\mathrm{TiO}_{2}$ or $\mathrm{ZnO}$ assisted photocatalysis, Fenton oxidation, and photo-Fenton reactions, ozonation and UV-assisted ozonation, as well as the combinations of these as reviewed in [5-7]. According to Perez et al. [5], UV-assisted ozonation is the most cost-efficient oxidation method. According to other research results [7-9], the Fenton oxidation performed with $\mathrm{H}_{2} \mathrm{O}_{2}$ and $\mathrm{FeSO}_{4}$ has also shown great potential in terms of effective removal of chlorinated organic compounds, and its cost-efficiency is significantly improved when the goal is partial chemical oxidation that yields more biodegradable compounds together with destruction of inhibitory species $[10,11]$.

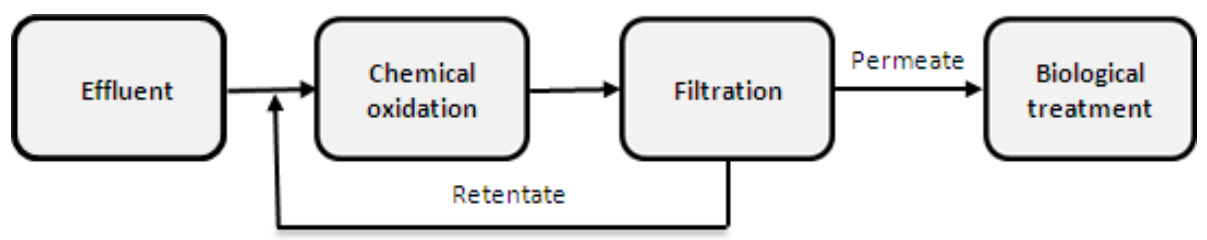

Fig. 1. Combining chemical oxidation, filtration and biological treatment.

The authors of the present research studied oxidative pre-treatments of bleaching effluent from hardwood kraft pulp production. The effluent contained chlorinated organic compounds. The oxidative pre-treatments, i.e. AOPs, included the Fenton oxidation, ozonation, as well as $\mathrm{TiO}_{2}$ and $\mathrm{ZnO}$-assisted photocatalytic processes. The efficiency of these pre-treatment methods at varied chemical doses and intensities was monitored by measuring the AOX and concentrations of selected chloroaromatic compounds in the effluents before and after the treatments. Some of the most cost-effective chemical doses of these oxidative treatments have been selected and applied to three ultrafiltration fractions of the effluent representing low, medium and high molecular weight fractions (LMW, MMW and HMW, respectively) of the dissolved organic material.

\section{EXPERIMENTAL}

Materials. Bleaching filtrates (effluents) were supplied by Metsä-Fibre's Äänekoski kraft pulp mill. The mill produces both hardwood (HW) and softwood (SW) pulp. The main bleaching agents are chlorine dioxide, oxygen and hydrogen peroxide. However, at the time of this research, the mill was producing chlorine dioxide with a $\mathrm{R} 3 \mathrm{H}$ generator system, which produced significant quantities of by-product chlorine. All by-product chlorine was used in bleaching which resulted in relatively high AOX concentrations in bleaching filtrates and effluents. After bleaching, acidic and alkaline filtrates were mixed, and the combined filtrate ( $\mathrm{pH}$ about 4) moved to the effluent treatment plant. 
The mill sample in this study was untreated effluent - before biological treatment - from a HW (birch, Betula pendula) kraft pulp production campaign.

Sodium hydroxide $(\mathrm{NaOH})$, sulfuric acid $\left(\mathrm{H}_{2} \mathrm{SO}_{4}\right)$, ferrous sulfate heptahydrate $\left(\mathrm{FeSO}_{4} \cdot 7 \mathrm{H}_{2} \mathrm{O}\right)$, titanium dioxide $\left(\mathrm{TiO}_{2}\right)$ and zinc oxide $(\mathrm{ZnO})$ were produced by Merck, while hydrogen peroxide $\left(\mathrm{H}_{2} \mathrm{O}_{2}\right)$ was supplied by Riedel-de Haën. All these chemicals were of analytical grade.

Analyses. The filtrate samples were kept in a freezer before they were sent to Oy Keskuslaboratorio-Centrallaboratorium $\mathrm{Ab}$ (KCL) for AOX analyses. KCL carried out AOX analyses according to EN-ISO 9562:2004. The Institute for Environmental Research (YMTK) quantitatively determined chlorinated phenols, catechols, and guaiacols. YMTK's analytical procedure to quantify chlorinated aromatics has been described in more detail elsewhere [12]. The AOX and chlorinated aromatics concentrations were calculated based on the production rate of the Äänekoski pulp mill, either as $\mathrm{kg} / \mathrm{ADt}$ or $\mathrm{mg} / \mathrm{ADt}$.

Fenton oxidation experiments. In the laboratory Fenton oxidation, the sample volumes were $250 \mathrm{~cm}^{3}$ for the first tests and $500 \mathrm{~cm}^{3}$ for the effluent fraction testing. The tests were conducted in Erlenmayer flasks equipped with on-line monitoring of temperature and $\mathrm{pH}$. The $\mathrm{pH}$ was set to 3 by adding $1 \mathrm{M}$ sulfuric acid. Hydrogen peroxide $(30 \%)$ and ferrous sulfate heptahydrate solutions were added to the samples, after which the treatment continued under continuous stirring for $2 \mathrm{~h}$ at $70^{\circ} \mathrm{C}$. The dosing combinations were based on two doses of hydrogen peroxide, $0.12 \mathrm{wt} . \%$ and $0.36 \mathrm{wt}$. \%, as well as two doses of ferrous sulfate, $0.5 \mathrm{mM}$ and $20 \mathrm{mM}$, respectively. The chemical doses are presented in Tables 1 and 2 . The doses are partially based on previous research by Rodríguez et al. [13].

Ozonation experiments. Ozonation was carried out by an Argentox Ozone Technology system. The duration of the ozonation treatment was $3 \mathrm{~min}$. In the first part of the research, the sample volume was $250 \mathrm{~cm}^{3}$, while in the ultrafiltration fraction test the volume was $500 \mathrm{~cm}^{3}$. The corresponding ozone doses were $360 \mathrm{mg} / \mathrm{dm}^{3}$ and $180 \mathrm{mg} / \mathrm{dm}^{3}$, respectively.

Photocatalytic experiments. The effluent was exposed to UV light ( $250 \mathrm{~W}$ halogen lamp and $10 \mathrm{~W}$ UV lamp) at distances of $50 \mathrm{~cm}$ and $12 \mathrm{~cm}$, respectively, from the reaction vessel. In a typical photocatalysis run, the quantity of the treated effluent was $200 \mathrm{~cm}^{3}$, except for the ultrafiltration fraction testing, which had an initial volume of $500 \mathrm{~cm}^{3}$. The semiconductors used in the experiments were $\mathrm{TiO}_{2}$ and $\mathrm{ZnO}$. The lowest $\mathrm{TiO}_{2}$ catalyst dose, $10 \mathrm{mg}$, was chosen according to Yeber et al. [14], while the other $\mathrm{TiO}_{2}$ doses tested were $100 \mathrm{mg}$ and $1 \mathrm{~g}$. The $\mathrm{ZnO}$ doses were $100 \mathrm{mg}$ and $1 \mathrm{~g}$. According 
to the research by Kansal et al. [15], the higher catalyst dosing increases photodegradation up to an optimal loading. In the effluent fraction testing, the doses for both semiconductors were $250 \mathrm{mg}$. The wavelength of the UV irradiation was $254 \mathrm{~nm}$. Irradiation times varied from $30 \mathrm{~min}$ to $2 \mathrm{~h}$. During the irradiation, the treated sample was agitated by injecting oxygen into the reaction vessel.

Pre-treatment of the effluent, and its fractionation by ultrafiltration. Effluent samples $\left(200 \mathrm{~cm}^{3}\right)$ were diluted to $2 \mathrm{dm}^{3}$ and their $\mathrm{pH}$ was set to 7.0 by adding $1 \mathrm{M}$ sodium hydroxide. To remove small particles, the samples were pre-filtrated with $0.8 \mu \mathrm{m}$ and $0.45 \mu \mathrm{m}$ membranes (Schleicher \& Schuell). Ultrafiltration was performed with a Millipore Pellicon Laboratory Cassette System using two regenerated cellulose membranes. Membranes had cut-off values of $5000 \mathrm{Da}$ and $1000 \mathrm{Da}$, which resulted in three sample fractions: <1000 Da (LMW), 1000-5000 Da (MMW), and >5000 Da (HMW). A more detailed description of the method has been presented elsewhere [16].

\section{RESULTS AND DISCUSSION}

Table 1 summarizes the concentrations of AOX and selected chlorinated aromatic substances, before and after respective chemical oxidation treatment. The most effective AOX removal (>90\%) was obtained by the Fenton oxidation with a lower ferrous sulfate $(0.5 \mathrm{mM})$, and a higher hydrogen peroxide $(0.36 \mathrm{wt}$. \%) doses. When both ferrous sulfate and hydrogen peroxide doses were high, $20 \mathrm{mM}$ and $0.36 \mathrm{wt} . \%$, respectively, the AOX removal was slightly over $80 \%$. Other combinations of ferrous sulfate and hydrogen peroxide, as well as other studied AOPs, resulted in much less efficient AOX removals. The most effective chemical doses of photocatalysis ( $\mathrm{UV}+100 \mathrm{mg} \mathrm{ZnO}, 1 \mathrm{~h}$ ) showed AOX removals of lower than $40 \%$, while ozonation only degraded less than $20 \%$ of the AOX.

The concentrations of chlorinated aromatics after the pre-treatments were quite well in agreement with those of AOX. The most complete removal of chloroaromatics was also achieved with the Fenton oxidation, especially when the hydrogen peroxide dose was higher $(0.36$ wt. \%). All measured polychlorinated substances were in that case below the detectable level. In terms of both AOX and chloroaromatics removal, photocatalysis appeared to be slightly more effective with $\mathrm{ZnO}$ than that with $\mathrm{TiO}_{2}$, which is in good agreement with the similar results reported by Kansal et al. [15]. The highest chloroaromatics removal rates for $\mathrm{ZnO}$ were over $60 \%$, while TiO-assisted photocatalysis only achieved a 50\% removal rate in one single case. Ozonation degraded about half of the chloroaromatics, removal rates ranging from about $30 \%$ to $70 \%$, depending on the chloroaromatic species. Therefore, ozonation seems to have more pronounced 
degrading effect on specific chlorinated aromatic substances than on AOX, the sum parameter. This is somewhat expected as the application of pure ozone oxidation is known to be limited by high selectivity and slow kinetics [17].

Table 1

Pre-treatments of the bleaching effluent under varied conditions

\begin{tabular}{|c|c|c|c|c|c|}
\hline \multirow[t]{2}{*}{ Sample } & \multirow{2}{*}{$\begin{array}{c}\mathrm{AOX} \\
{[\mathrm{kg} / \mathrm{ADt}]}\end{array}$} & $\begin{array}{c}2,6 \text {-dichloro- } \\
\text { phenol }\end{array}$ & $\begin{array}{c}2,4,6 \text {-trichloro- } \\
\text { phenol }\end{array}$ & $\begin{array}{c}3,4,5 \text {-trichloro- } \\
\text { catechol }\end{array}$ & $\begin{array}{c}4,5,6 \text {-trichloro- } \\
\text { guaiacol }\end{array}$ \\
\hline & & \multicolumn{4}{|c|}{ [mg/ADt] } \\
\hline Untreated alkaline filtrate & 1.04 & 19.5 & 40.8 & 15.4 & 44.0 \\
\hline 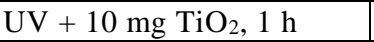 & 0.88 & 12.6 & 34.5 & 12.2 & 25.4 \\
\hline $\mathrm{UV}+100 \mathrm{mg} \mathrm{TiO} 2,1 \mathrm{~h}$ & 1.00 & 14.1 & 37.7 & 12.6 & 25.7 \\
\hline $\mathrm{UV}+1 \mathrm{~g} \mathrm{TiO}_{2}, 1 \mathrm{~h}$ & 0.97 & 12.6 & 37.7 & 13.8 & 23.5 \\
\hline 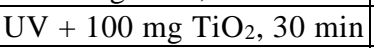 & 0.91 & 11.6 & 34.5 & 13.2 & 22.0 \\
\hline 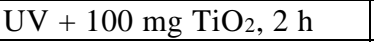 & 0.97 & 11.6 & 34.5 & 11.0 & 25.1 \\
\hline $\mathrm{UV}+100 \mathrm{mg} \mathrm{ZnO}, 1 \mathrm{~h}$ & 0.63 & 7.85 & 29.5 & 7.22 & 29.8 \\
\hline $\mathrm{UV}+1 \mathrm{~g} \mathrm{ZnO}, 1 \mathrm{~h}$ & 0.66 & 11.0 & 34.5 & 8.16 & 34.5 \\
\hline $\mathrm{UV}+100 \mathrm{mg} \mathrm{ZnO,} 2 \mathrm{~h}$ & 0.66 & 10.0 & 29.5 & 5.65 & 28.6 \\
\hline $360 \mathrm{mg} \mathrm{O}_{3} / \mathrm{dm}^{3}$ & 0.85 & 5.97 & 16.6 & 10.4 & 21.3 \\
\hline $\begin{array}{l}0.5 \mathrm{mM} \mathrm{FeSO}_{4} \\
+0.12 \text { wt. } \% \mathrm{H}_{2} \mathrm{O}_{2} \\
\end{array}$ & 0.53 & BDL & 3.45 & 5.34 & 2.6 \\
\hline $\begin{array}{l}20 \mathrm{mM} \mathrm{FeSO}_{4} \\
+0.12 \text { wt. } \% \mathrm{H}_{2} \mathrm{O}_{2} \\
\end{array}$ & 0.41 & 18.2 & 10.4 & 5.02 & 3.45 \\
\hline $\begin{array}{l}0.5 \mathrm{mM} \mathrm{FeSO}_{4} \\
+0.36 \text { wt. } \% \mathrm{H}_{2} \mathrm{O}_{2}\end{array}$ & 0.09 & \multirow{2}{*}{\multicolumn{4}{|c|}{ below detection limit }} \\
\hline $\begin{array}{l}20 \mathrm{mM} \mathrm{FeSO}_{4} \\
+0.36 \text { wt. } \% \mathrm{H}_{2} \mathrm{O}_{2}\end{array}$ & 0.19 & & & & \\
\hline
\end{tabular}

In the latter part of the research, larger effluent samples were subjected to oxidation with the most promising chemical doses, after which they underwent ultrafiltration. This resulted in three fractions of effluent, based on the molecular weight of the dissolved substances: LMW, MMW and HMW fractions. The measured AOX concentrations of the respective effluent fractions are presented in Table 2. The data shows that the higher hydrogen peroxide dose $\left(0.5 \mathrm{mM} \mathrm{FeSO} 4+0.36\right.$ wt. $\left.\% \mathrm{H}_{2} \mathrm{O}_{2}\right)$ resulted in the highest removal of AOX, which is highlighted in the HMW fraction of the effluent. Also the lower hydrogen peroxide dose $\left(20 \mathrm{mM} \mathrm{FeSO}_{4}+0.12\right.$ wt. $\left.\% \mathrm{H}_{2} \mathrm{O}_{2}\right)$ was able to degrade most of the AOX in the HMW fraction. The corresponding HMW AOX removal efficiencies were $90 \%$ and $80 \%$, respectively. AOX removals in the MMW fraction were about $80 \%$ and $75 \%$, respectively. On the other hand, the decrease in AOX concentration with the same chemical doses is less pronounced in the LMW fractions, less than 
$50 \%$. This can be partially explained by the degradation of HMW and MMW chlorinated organic compounds into the LMW category.

Table 2

AOX concentrations in ultrafiltrated effluent fractions

\begin{tabular}{|c|c|c|}
\hline Fraction & Sample & $\begin{array}{c}\mathrm{AOX} \\
{[\mathrm{kg} / \mathrm{ADt}]}\end{array}$ \\
\hline LMW & \multirow{3}{*}{ untreated effluent } & 0.37 \\
\hline MMW & & 0.14 \\
\hline HMW & & 0.67 \\
\hline LMW & \multirow{3}{*}{$\mathrm{UV}+250 \mathrm{mg} \mathrm{TiO} 2,1 \mathrm{~h}$} & 0.35 \\
\hline MMW & & 0.14 \\
\hline HMW & & 0.57 \\
\hline LMW & \multirow{3}{*}{$\mathrm{UV}+250 \mathrm{mg} \mathrm{ZnO}, 1 \mathrm{~h}$} & 0.25 \\
\hline MMW & & 0.10 \\
\hline HMW & & 0.44 \\
\hline LMW & \multirow{3}{*}{$180 \mathrm{mg} \mathrm{O}_{3} / \mathrm{dm}^{3}$} & 0.21 \\
\hline MMW & & 0.08 \\
\hline HMW & & 0.38 \\
\hline LMW & \multirow{3}{*}{$0.5 \mathrm{mM} \mathrm{FeSO}_{4}+0.36$ wt. $\% \mathrm{H}_{2} \mathrm{O}_{2}$} & 0.21 \\
\hline MMW & & 0.03 \\
\hline HMW & & 0.06 \\
\hline LMW & \multirow{3}{*}{$20 \mathrm{mM} \mathrm{FeSO}_{4}+0.12$ wt. $\% \mathrm{H}_{2} \mathrm{O}_{2}$} & 0.19 \\
\hline MMW & & 0.04 \\
\hline HMW & & 0.14 \\
\hline
\end{tabular}

In this research, AOX removal efficiencies of other chemical oxidative treatments were clearly lower than those of the Fenton oxidation. $\mathrm{TiO}_{2}$-assisted photocatalysis only had a minor effect on the effluent fractions, while $\mathrm{ZnO}$-assisted photocatalysis degraded about one third of the AOX in all fractions. Ozonation performed similarly to $\mathrm{ZnO}-$ -assisted photocatalysis. However, it should be noted that none of the studied AOPs were completely optimized.

\section{CONCLUSIONS}

This research demonstrated that the Fenton process is an established AOP technology that is able to selectively degrade AOX, and virtually all highly chlorinated aromatics in kraft pulp mill effluents. The highest removal efficiency was achieved with $\mathrm{FeSO}_{4}$ and $\mathrm{H}_{2} \mathrm{O}_{2}$ concentrations of $0.5 \mathrm{mM}$ and $0.36 \mathrm{wt}$. \%, respectively. Photocatalytic oxidation and ozonation showed much lower removal efficiencies in this study. 
The efficient degradation of AOX in the high molecular weight fraction of the effluent by Fenton oxidation suggests that by adding a filtration step, the remaining higher molecular weight fractions can be returned to the Fenton oxidation and therefore almost all HMW and MMW AOX can be degraded before biological treatment. The resulting degradation products are more reactive and more susceptible to biodegradation, which significantly improves the overall efficiency of the effluent treatment system as well as effluent quality.

\section{ACKNOWLEDGEMENTS}

This research was financially supported by Metsä-Botnia Oyj (now: Metsä Fibre Oyj), which is gratefully acknowledged.

\section{REFERENCES}

[1] Hynninen P., Effluent loadings from the forest industry, [in:] P. Hynninen (Ed.), Environmental Control, Fapet Oy, Jyväskylä, Finland, 1998, 30.

[2] FiSKARI J., On minimum effluent pulp mill concept: water use reduction in the bleach plant, Doctoral Thesis, Åbo Akademi University, Åbo, Finland, 2002.

[3] KNUUtinen J., AlÉN R., Overview of analytical methods in wet-end chemistry, [in:] R. Alén (Ed.), Papermaking Chemistry, Fapet Oy, Jyväskylä, Finland, 2007, 199.

[4] Ali M., SReEkrishnan T.R., Aquatic toxicity from pulp and paper mill effluents. A review, Adv. Environ. Res., 2001, 5 (2), 175.

[5] PÉREZ M., TORRADES F., DOMÈNECH X., PERAl J., Treatment of bleaching kraft mill effluents and polychlorinated phenolic compounds with ozonation, J. Chem. Technol. Biotechnol., 2002, 77 (5), 891.

[6] MantZavinos D., Psillakis E., Enhancement of biodegrability of industrial wastewaters by chemical oxidation pre-treatment, J. Chem. Technol. Biotechnol., 2002, 79 (5), 431.

[7] CATAlKayA E.C., KARGi F., Color, TOC and AOX removals from pulp mill effluent by advanced oxidation processes. A comparative study, J. Hazard. Mater., 2007, 139 (2), 244.

[8] Cajal-Mariñosa P., Mononen T., Fiskari J., TuhKanen T., A novel concept for monitoring AOX and DOC removal during Fenton treatment of bleached kraft pulp mill effluents, Tappsa J., 2012, (3), 23.

[9] IsOAho J.P., TARKKANEN S., AlÉN R., FisKARi J., Oxidative degradation of AOX in softwood-based kraft mill effluents from ECF bleaching, Nord. Pulp Pap. Res. J., 2012, 27 (4), 707.

[10] Marco A., Esplugas S., Saum G., How and why combine chemical and biological processes for wastewater treatments, Water Sci. Technol., 1997, 35 (4), 321.

[11] Chamarro E., MARCo A., EsPlugas S., Use of Fenton reagent to improve organic chemical biodegrability, Water Res., 2001, 35 (4), 1047.

[12] Mäntykoski K., PCBs in Processes, Products and Environment of Paper Mills Using Wastepaper as Their Raw Material, Doctoral Thesis, University of Jyväskylä, Jyväskylä, Finland, 2006.

[13] Rodríguez J., Contreras D., Parra C., Freer J., Baeza J., DurÁn N., Pulp mill effluent treatment by Fenton-type reactions catalyzed by iron complexes, Water Sci. Technol., 1999, 40 (11-12), 351.

[14] Yeber M.C., Rodríguez J., FreEr J., ZARor C., DurÁn N., MANsilla H.D., Photocatalytic degradation of cellulose bleaching effluent by supported $\mathrm{TiO}_{2}$ and $\mathrm{ZnO}$, Chemosphere, 2000, 41 (8), 1193.

[15] KAnsal S.K., Singh M., Sud D., Studies on $\mathrm{TiO}_{2} / \mathrm{ZnO}$ photocatalysed degradation of lignin, J. Hazard. Mater., 2008, 153 (1-2), 412. 
[16] Ristolainen M., ALÉn R., KNUUTINEN J., Characterization of TCF effluents from kraft pulp bleaching. I. Fractionation of hardwood lignin-derived material by GPC and UF, Holzforschung, 1996, 50 (1), 91.

[17] KoPRIVANAC N., KUSIC H., AOP as an effective tool for the minimization of hazardous organic pollutants in colored wastewater; Chemical and photochemical processes, [in:] A. Lewinsky (Ed.), Hazardous Materials and Wastewater: Treatment, Removal and Analysis, Nova Science Publishers, Inc., New York 2007, 149. 